\title{
Monocyte/macrophage inflammatory response pathways to combat Francisella infection: possible therapeutic targets?
}

\section{Devyn D. Gillette, Susheela Tridandapani and Jonathan P. Butchar*}

Department of Internal Medicine, Wexner Medical Center, The Ohio State University, Columbus, OH, USA

Edited by:

Max Maurin, Université

Aix-Marseille II, France

\section{Reviewed by:}

Marina Santic', University of Rijeka,

Croatia

Chad J. Roy, Tulane University, USA

*Correspondence:

Jonathan P. Butchar, Division of

Pulmonary, Allergy, Critical Care and

Sleep Medicine, Wexner Medical

Center, 201 Davis Heart and Lung

Research Institute, The Ohio State

University, 473 West 12th Avenue,

Columbus, OH 43210, USA

e-mail: jon.butchar@osumc.edu
Francisella tularensis can bypass and suppress host immune responses, even to the point of manipulating immune cell phenotypes and intercellular inflammatory networks. Strengthening these responses such that immune cells more readily identify and destroy the bacteria is likely to become a viable (and perhaps necessary) strategy for combating infections with Francisella, especially given the likelihood of antibiotic resistance in the foreseeable future. Monocytes and macrophages offer a niche wherein Francisella can invade and replicate, resulting in substantially higher bacterial load that can overcome the host. As such, understanding their responses to Francisella may uncover potential avenues of therapy that could promote a lowering of bacterial burden and clearance of infection. These response pathways include Toll-like Receptor 2 (TLR2), the caspase-1 inflammasome, Interferons, NADPH oxidase, Phosphatidylinositide 3-kinase (PI3K), and the Ras pathway. In this review we summarize the literature pertaining to the roles of these pathways during Francisella infection, with an emphasis on monocyte/macrophage responses. The therapeutic targeting of one or more such pathways may ultimately become a valuable tool for the treatment of tularemia, and several possibilities are discussed.

Keywords: Francisella, monocytes, macrophages, signaling, host response

\section{INTRODUCTION}

Francisella tularensis is the Gram-negative causative agent of tularemia (Sjostedt, 2007). F. tularensis has been classified into distinct subspecies, including $F$. tularensis subsp. tularensis (F. tularensis; Type A), F. tularensis subsp. holarctica (F. holarctica; Type B), and F. tularensis subsp. novicida (F. novicida), which may actually be a separate species (Johansson et al., 2010). Francisella is especially recognized for its low infectious dose and ability to cause severe illness and death, which justifies its categorization as a Category A select agent by the USA Centers for Disease Control and Prevention (CDC) (Sjostedt, 2007). Of note, the most life-threatening forms of tularemia are particularly associated with Type A infections regardless of host species (Mohapatra et al., 2013). Although known to infect a range of host organisms and cell types (Rick and Wu, 2007; Hall et al., 2008), F. tularensis has evolved to successfully infect human monocytes/macrophages where the bacteria escape the phagosome, replicate within the cytosol and then move on to other cells as the infected cells die (Clemens and Horwitz, 2007; Elkins et al., 2007; Jones et al., 2012; Celli and Zahrt, 2013). In vivo, macrophages appear to be the preferred host cell for Francisella (Sjostedt, 2003; Elkins et al., 2007).

One critical characteristic of $F$. tularensis is its ability to attenuate host inflammatory responses. Indeed, early studies in humans showed that Franicsella-infected individuals exhibited diminished cytokine responses to endotoxin (Greisman et al., 1963).
In the murine system $F$. tularensis infection does not lead to a classic pro-inflammatory cytokine response, and this results in insufficient numbers of immune cells recruited to infection sites (Bosio et al., 2007). Further, murine studies have corroborated the findings of Greisman et al. (1963), who found that challenge with lipopolysaccharide (LPS) after infection did not lead to the production of pro-inflammatory cytokines such as Tumor Necrosis Factor $\alpha(\mathrm{TNF} \alpha)$ in mouse cell lines nor in vivo (Telepnev et al., 2003, 2005; Bosio, 2011). Similar findings have also been observed in F. tularensis-infected murine bonemarrow and alveolar macrophages following administration of the synthetic triacylated lipopeptide $\mathrm{Pam}_{3} \mathrm{CSK}_{4}$ (Crane et al., 2013).

Circulating monocytes constitute lower than $10 \%$ of blood immune cells, yet serve a critical role as primary responders to infection (Moser and Loetscher, 2001; Leavy, 2012). As mentioned above they are also prime targets of Francisella infection. Along with this, a higher percentage of monocytes are infected by $F$. tularensis than either $F$. holarctica or $F$. novicida during the course of infection (Hall et al., 2008). The focus of this brief review is on some of the critical intracellular response pathways involved with Francisella infection. The role of each pathway during $F$. tularensis infection is summarized, with an emphasis on monocyte/macrophage responses. Following this is a short discussion of potential non-antibiotic means of combating Francisella by modulating these response pathways. 


\section{Francisella AND TOLL-LIKE RECEPTORS}

Host immune cells have evolved to contain an array of receptors which are vital for the detection of invading microbes and foreign materials. These surface- and endosomally-expressed sensors, termed pattern recognition receptors (PRR), can recognize highly conserved bacterial, viral, and fungal motifs (Brown et al., 2011). Toll-Like Receptors (TLR) are key PRR that are expressed by a variety of cells including monocytes and macrophages. Francisella directly interacts with the host cell through TLR2, a surface receptor that recognizes surface lipopeptides and peptidoglycan. In fact, TLR2 ${ }^{-/-}$mice infected with $F$. tularensis Live Vaccine Strain (LVS) display markedly lower TNF $\alpha$ and Interleukin 6 (IL-6) production, decreased Nuclear factor kappalight-chain-enhancer of activated B cells (NF- $\mathrm{B}$ ) activation, and showed overall lower survival when compared to wild-type mice (Katz et al., 2006; Malik et al., 2006). Specific lipopeptides that can induce TLR2 signaling, particularly the triacylated $17-\mathrm{kDa}$ membrane lipoprotein FTT0901/TUL4/LpnA (Sandstrom et al., 1987; Sjostedt et al., 1989, 1991) and the membrane lipoprotein FTT1103/FipB (Francisella infectivity potentiator protein B) (Qin and Mann, 2006; Qin et al., 2011), are present on Francisella's surface (Thakran et al., 2008).

Modifications in TLR2 expression levels are associated with Francisella infections, and these can vary depending on the subspecies. For example, we have shown that F. novicida significantly increased TLR2 transcript after infection in primary monocytes while F. tularensis Schu S4 decreased it (Butchar et al., 2008). In addition to altering receptor expression, both F. tularensis and F. novicida can downregulate the molecule Cluster of differentiation 14 (CD14) (Butchar et al., 2008). This is an important co-receptor for both TLR2 and TLR4. It is required by the host cell in order to generate a potent pro-inflammatory cytokine response to F. tularensis LVS, although it is not adequate for increasing survival in vivo (Chase and Bosio, 2010). In like manner, recent reports highlight the role of the downstream adapter Myeloid differentiation primary response 88 (MyD88), as mice lacking this molecule died rapidly when challenged with F. tularensis LVS (Collazo et al., 2006).

The importance of TLR4 in responding to LPS has long been recognized (Chow et al., 1999; Qureshi et al., 1999). Francisella, however, expresses an atypical LPS that does not strongly induce TLR4 (Duenas et al., 2006). This is attributed to the lack of two acetyl groups in its LPS, making it incapable of inducing a strong TLR4 response (Phillips et al., 2004). TLR signaling appears to be very effectively subverted by Francisella, and this may position TLR as well as downstream pathway members as prime candidates for targeted therapy (discussed in a later section).

\section{INFLAMMASOME RESPONSES}

Cystolic sensing mechanisms such as the multi-protein inflammasome play a prominent role in recognizing intracellular pathogens, including Francisella. This depends upon Francisella's escape from the phagolysosome (Mariathasan et al., 2005; Gavrilin et al., 2006). Inflammasomes regulate caspase activation through proteolytic cleavage, leading to Interleukins $1 \beta$ and 18 (IL-1 $\beta$ and IL-18) processing. Cleavage of procaspase1 to caspase- 1 requires TLR2, as TLR2 ${ }^{-/-}$mouse macrophages showed little caspase-1 $24 \mathrm{~h}$ after infection with LVS (Dotson et al., 2013). Expectedly, caspases have been implicated in the regulation of Francisella infections. For example, mice lacking caspase-1 displayed higher bacterial numbers in organs following infection with F. novicida (Mariathasan et al., 2005; Jones et al., 2010).

Francisella's escape from the phagosome triggers Absent in Melanoma 2 (AIM2) inflammasome activation, as a subset of F. novicida have been shown to lyse within the cytosol and release AIM2-activating double-stranded deoxyribonucleic acid (dsDNA) (Fernandes-Alnemri et al., 2010; Jones et al., 2010; Rathinam et al., 2010). The importance of AIM2 in Francisella infection was clearly demonstrated by a study showing that AIM2 ${ }^{-/-}$mice had increased organ bacterial burden and lower survival rates than wild-type following infection with $F$. novicida (Fernandes-Alnemri et al., 2010). In humans however, it has been shown that the NALP3 inflammasome was the primary driver of IL- $1 \beta$ production, with AIM2 contributing as well (Atianand et al., 2011).

The influence of Francisella on inflammasome activity appears to be subspecies-dependent. For example, recent data suggest that $F$. novicida does not inhibit inflammasome activation (Broz and Monack, 2011). In contrast, it has been shown that LVS delays inflammasome activation and cell death, an activity that requires the OmpA-like Francisella protein FTL_0325. In vivo, mice infected with LVS harboring a mutation in FTL_0325 showed significantly higher IL- $1 \beta$ by the first day after infection while mice infected with control LVS showed higher IL-1 $\beta$ at day 3. Importantly, mice infected with the LVS mutant that permitted earlier inflammasome activation showed a significantly lower bacterial load at day 3 (Dotson et al., 2013).

Virulent Francisella manipulates inflammasome responses by stimulating the activation of apoptosis-promoting caspase3 rather than caspase-1 (Wickstrum et al., 2009; Bosio, 2011). Tissues from Type A F. tularensis infected mice expressed increased cleaved caspase-3, in contrast to the tissue responses of F. tularensis LVS- and F. novicida-infected mouse macrophages. In these cells, an increased caspase- 1 dependent/caspase- 3 independent inflammatory cytokine production was more evident (Wickstrum et al., 2009).

\section{TYPE I AND II INTERFERONS}

Interferons (IFNs) are host-produced proteins with an inherent role in pathogen clearance during infection. These Type I interferons induce signal transduction molecules, upregulate major histocompatibility complex (MHC) molecules and promote proliferation of $\mathrm{T}$ cells (Welsh et al., 2012). Importantly, they have been shown to be critical for inflammasome activation in response to Francisella (Henry et al., 2007). While usually associated with viral infections, interferons are also seen with Francisella infection. For example, F. novicida is able to induce a variety of Type I IFN-associated genes in mouse bone marrow-derived macrophages (BMM) (Henry et al., 2007), and Schu S4 upregulated IFN $\beta$ in human peripheral blood monocytes (Butchar et al., 2008). However, it has been shown that Francisella suppresses Type I interferon signaling. For example, the virulent F. tularensis strain Schu S4 inhibited the ability of dendritic cells to 
produce IFN $\alpha$ and IFN $\beta$ (Chase et al., 2009). Infection of human monocytes with Schu S4 led to downregulation of IFN $\alpha$ receptors 1 and 2 (Butchar et al., 2008). As such, it appears as though the more virulent form of Francisella uses more than one means to combat Type I IFN signaling.

It has also been shown that infection of human primary monocytes with F. tularensis and F. holarctica not only leads to downregulation of Type I interferon pathway components but also Type II (Butchar et al., 2008; Cremer et al., 2011). IFN $\gamma$, a cytokine produced primarily by natural killer $(\mathrm{NK})$ and $\mathrm{T}$ cells, regulates the immunological response to effectively clear pathogens. IFN $\gamma$ can lower bacterial number following infection with LVS (Anthony et al., 1989; Polsinelli et al., 1994), and can reduce the intra-macrophage growth of LVS in a dose-dependent manner (Anthony et al., 1992). Later reports demonstrated that macrophages treated with IFN $\gamma$ were more efficient in clearing Francisella via an increased ability to perform phagosomelysosomal fusion (Santic et al., 2005). In human monocytes, both F. tularensis and F. novicida increased IFN $\gamma$ ligand expression but decreased IFN $\gamma$ Receptor 1 (Butchar et al., 2008). In conjunction, it has been shown in both human and murine monocytic cell lines that F. novicida induces Suppressor of Cytokine Signaling 3 (SOCS3) expression, suppresses Signal Transducer and Activator of Transcription 1 (STAT1) phosphorylation, and suppresses both Interferon gamma-induced protein 10 (IP-10) and Inducible Nitric Oxide Synthase (iNOS) production (Parsa et al., 2008a).

Because of the Francisella-mediated dampening of both Type I and Type II interferon signaling, there is a possibility that pharmaceutical delivery of interferons may help combat infection. Intron A (Spiegel, 1985), Rebif (Mantia et al., 2013), and Actimmune (Todd and Goa, 1992) are clinically approved drugs that deliver interferons alpha, beta, and gamma to the patient, respectively. They have been utilized for the management of Multiple Sclerosis, Chronic Granulomatous Disease (CGD), and Hepatitis B infection, but there is a possibility that one or more may aid against at least some forms of tularemia.

Another Francisella family member, F. philomiragia, is an opportunistic pathogen found with immunocompromised individuals. In particular, it is associated with the abovementioned CGD, which can lead to fatal septicemia (Seger et al., 1982; Mailman and Schmidt, 2005). Interestingly, both F. tularensis and F. philomiragia have been associated with chronic granulomas and necrotizing abscesses (Schmid et al., 1983; Nylund et al., 2006). Of particular importance, $F$. philomiragia has between a $70-85 \%$ homology to F. tularensis (Whipp et al., 2003), suggesting that both pathogens may to some degree respond to IFN treatment. However, Melillo et al. (2010) showed that IFN $\gamma$ did not improve the ability of human macrophages to combat Schu S4. Further testing, perhaps with the use of monocytes, or using IFN $\gamma$ plus other agents, may uncover a positive role of IFN $\gamma$ against virulent Francisella.

\section{THE ROLE OF NADPH}

Target host cells of Francisella can respond to infection with the production of reactive oxygen species (ROS) and reactive nitrogen species (RNS) (Lindgren et al., 2005). Here we will focus on ROS, which are generated following the assembly of nicotinamide adenine dinucleotide phosphate-oxidase (NADPH oxidase) and are a crucial innate defense mechanism. Not surprisingly, however, Francisella has devised an array of techniques to inhibit ROS. These include techniques focused on hindering NADPH component assembly, obstructing ROS production from assembled NADPH oxidases and neutralizing generated ROS (Bosio, 2011; Jones et al., 2012). Francisella, including both virulent and less virulent strains, reduces ROS production in neutrophils and macrophages. The acid phosphatase AcpA has been shown to be important for inhibiting reactive oxygen species production in both macrophages and neutrophils (Mohapatra et al., 2010). Another report showed that in neutrophils, virulent F. tularensis both with and without an AcpA mutation, suppressed the production of superoxide anions from the NADPH oxidase complex (McCaffrey et al., 2010).

The live vaccine strain of $F$. tularensis was able to persist within neutrophils by avoiding acquisition of gp91/p22 plasma membrane and p47/p67 cytosolic NADPH subunits (McCaffrey and Allen, 2006). This supported the growth of F. tularensis LVS by hindering NADPH assembly. The importance of altering NADPH complexes is not unique to Francisella, as multiple bacteria including Helicobacter pylori and Salmonella typhimurium have been shown to alter NADPH oxidase assembly in cells (Gallois et al., 2001; Allen et al., 2005). If Francisella does encounter ROS, catalases and super oxide dismutases (SOD) enzymes are necessary for survival, as $\triangle$ SOD F. tularensis LVS have increased susceptibility to IFN $\gamma$-induced death (Melillo et al., 2009). Indeed, it has been shown that antioxidants produced by Francisella Schu S4 can dampen macrophage inflammatory responses (Melillo et al., 2010).

\section{THE PI3K/Akt PATHWAY}

Phosphatidylinositol 3'-kinase (PI3K) leads to activation of Akt, also known as protein kinase $\mathrm{B}$ (PKB/Akt) [please see (Hers et al., 2011; Hemmings and Restuccia, 2012) for brief reviews on the PI3K/Akt pathway, and (Cremer et al., 2011) for a short review within the context of Francisella]. The cellular processes mediated by PI3K include phagocytosis (Araki et al., 1996), autophagy (Petiot et al., 2000), cytokine production (Parsa et al., 2006), and oxidative burst (Chen et al., 2003; Hoyal et al., 2003). Hence, manipulation of PI3K may be advantageous for pathogens. For example, macrophages from PI3K-deficient mice show impaired nitric oxide production and increased predisposition to Chlamydia pneumoniae infection (Sakai et al., 2006). Stimulation of the PI3K/Akt pathway has downstream positive effects on NF- $\kappa \mathrm{B}$ activation and host response (Rajaram et al., 2006). It has also been reported that PI3K and Akt are crucial in the production of RANTES ("regulated on activation, normal T cell expressed and secreted"), IL-6, and IL-12 following F. novicida infections (Parsa et al., 2006; Rajaram et al., 2006). F. tularensis Schu S4 but not F. novicida leads to downregulation of the regulatory p85 subunit of PI3K, as well as Akt itself (Butchar et al., 2008). Conversely, mice expressing constitutively active Akt (MyrAkt) did not succumb to F. novicida infections to the same extent as wild-type mice (Rajaram et al., 2006). Initiation of these pathways favors the host largely through the activation of NF- $\kappa \mathrm{B}$, which promotes survival, cytokine production, and phagosomal 
maturation (Telepnev et al., 2005; Parsa et al., 2006). However, it has also been reported that wortmannin, by blocking Akt activation and mitogen-activated protein kinase phosphatase 1 (MKP1) upregulation, could enhance Mitogen-activated Protein Kinase 1 (MAPK1) and phosphorylation of the p38 MAPK, as well as cytokine release in murine BMM following infection with LVS (Medina et al., 2010). It was also shown that Complement component 3 (C3) opsonization of Schu S4 led to phosphorylation of Akt in human monocyte-derived macrophages (MDM) and that this led to an upregulation of the Erk inhibitor MKP-1 (Dai et al., 2013). Further experiments may be needed to tease out the role(s) of Akt during Francisella infection, but the differences seen are likely due to differences in complement, in bacterial subspecies and/or cell type. The results of Dai et al., however, point to the C3 pathway as a putative therapeutic target.

Downstream inhibitors of PI3K have also been shown to be involved with dampening responses following Francisella infection. Deletion of a key phosphatase, Phosphatidylinositol3,4,5-trisphosphate 5-phosphatase 1 (SHIP1) has been shown to permit greater cytokine production following infection of primary murine macrophages with F. novicida (Parsa et al., 2006). In addition, Phosphatase and tensin homolog (PTEN) is upregulated following Francisella Schu S4 infection of human MDM (Melillo et al., 2010). Both phosphatases serve to dampen PI3K activity, resulting in a lessening of responses such as cytokine production. SHIP1 has also been shown to attenuate Ras activity by binding Shc (Damen et al., 1996). MicroRNAs (miRs) are posttranscriptional regulators of gene expression and Francisella has developed methods to use microRNAs to its advantage (Cremer et al., 2009; Eulalio et al., 2012). Specifically, miR-155, which targets the $3^{\prime}$ UTR of SHIP1, is induced by F. novicida but not Schu S4, resulting in higher levels of SHIP1 with Schu S4 (Cremer et al., 2009).

\section{THE RAS PATHWAY}

Francisella also modulates the Ras-Raf-MAPK kinase-MAPK signaling pathway during infection (Al Khodor and Abu, 2010; Asare and Abu Kwaik, 2010). It has been shown that intracellular F. novicida triggers Ras activation within $15 \mathrm{~min}$ in human MDM. This occurs through Son of Sevenless 2 (SOS2)/Growth factor receptor-bound protein $2(\mathrm{GRB} 2) /$ Protein kinase $\mathrm{C} \alpha(\mathrm{PKC} \alpha)$ and Protein kinase $C \beta 1$ (PKC $\beta 1)$, which are essential for bacterial proliferation (Al Khodor and Abu, 2010). Along with proliferation, the Ras pathway has been linked to cell death associated with Francisella infection. Inhibition of MAPK1 phosphorylation prevented LVS-induced apoptosis in the J774.2 mouse macrophage cell line (Hrstka et al., 2005). Uptake of F. novicida also depends on MAPK1, via activation of Spleen tyrosine kinase (Syk) (Parsa et al., 2008b). Ras activation upon infection is not specific to F. novicida, as Listeria monocytogenes and Helicobacter pylori promote Ras activation during infection (Keates et al., 2001; Mansell et al., 2001).

In contrast to observations with $F$. novicida, it has been shown that C3-opsonized Schu S4 dampens activation of MAPK1, p38 MAPK, and NF- $\mathrm{B}$, along with cytokine production in human monocyte-derived macrophages (Dai et al., 2013). Cytokine responses to non-opsonized Schu S4 were stronger, although not as strong as the responses to F. novicida, and C3 opsonization did not alter the responses to F. novicida (Dai et al., 2013). These C3-mediated dampening effects appeared to be due to activation of the protein tyrosine kinase LYN (Dai et al., 2013). Hence, it appears as though there are differences in response to $F$. novicida and F. tularensis that suggest caution when making inferences from one to the other. Additional studies will be required in order to tease out the intricacies of virulent Francisella and Ras.

Effectively targeting the Ras pathway may provide a novel means of combating F. tularensis. Celecoxib, an FDA-approved cyclooxygenase 2 (COX-2) inhibitor normally administered as an anti-inflammatory agent, has recently been implicated in the upregulation of MAPK1 and/or p38 MAPK activity in head and neck squamous cell carcinoma cell lines, inhibiting their proliferation (Park et al., 2010). Importantly, a potent antimicrobial activity of celecoxib and a derivative has been reported, which appears specific against Francisella. Celecoxib and a pharmacologic derivative termed Compound 20, killed F. novicida, LVS, and Schu S4 in growth media. In addition, compound 20 inhibited the growth of F. novicida and Schu S4 in Raw 264.7 mouse macrophage cells (Chiu et al., 2009). Hence, celecoxib or related compounds may offer a dual effect against Francisella: promoting host cell responses and direct killing.

\section{CAN WE FIGHT Francisella WITHOUT ANTIBIOTICS?}

Research to date points to immunosuppression as a critical factor in the virulence of Francisella. This leads to the hypothesis that enhancing inflammatory responses would serve to combat infection. Although cytokines such as TNF $\alpha$, IL-1 $\beta$, and IFN $\gamma$ are known to activate certain aspects of cellular immune responses and are known to be attenuated by Francisella, treatment with these or other such agents may not be sufficient to combat an antibiotic-resistant form of this pathogen. For example, even though IFN $\gamma$ may promote phago-lysosomal fusion upon infection with the less virulent F. novicida (Santic et al., 2005), it does not appear to protect human MDM against Schu S4 (Melillo et al., 2010). Hence, although IFN $\gamma$ may be important for combating Francisella, it in itself is not sufficient. Likewise, the specific therapeutic targeting of other pathways may not be sufficient to mount a successful immune response against Francisella. Another approach may be to stimulate the production and activation of monocytes through administration of a factor such as Granulocyte-macrophage colony-stimulating factor (GM-CSF). This factor acts on both monocytes and neutrophils, and has been tested extensively as an antitumor agent (Waller, 2007). Along with this, it can enhance the activity, including respiratory burst, of monocytes as has been shown ex vivo with septic patient monocytes (Williams et al., 1998). Although GM-CSF did not reduce intra-macrophage growth of LVS (Anthony et al., 1992), there is a possibility that it may show some efficacy in vivo.

Alternatively, it is likely that the simultaneous activation of multiple immune response pathways will be required. One potential non-antibiotic-based treatment that has already made its way into the cancer arena is the use of immunomodulatory agents. Indeed, this is being actively pursued as a potential treatment for sepsis as well as for several viral and bacterial infections (reviewed in Savva and Roger, 2013). 
Immunomodulators have been studied and used for the treatment of cancer for well over 100 years. Tumors exert a strong immunosuppressive effect on host immune responses, even to the point where they co-opt immune cells for the production of factors that promote growth, survival, and angiogenesis (Becker et al., 2013; Kushner and Bautch, 2013). From this perspective, perhaps there are enough similarities between Francisella and tumor cells with regard to immunosuppression [e.g., both involve Transforming growth factor $\beta$ (TGF $\beta$ ) production (Bosio et al., 2007; Becker et al., 2013)] that these compounds would be effective in treating tularemia. In fact, it has recently been shown that administration of a TLR4 agonist conferred protection against F. novicida infection in mice (Lembo et al., 2008). It was later shown that a mix of DNA-liposome complexes plus Francisella membrane fractions could protect mice from $F$. tularensis infection (Ireland et al., 2010).

The first promising immunomodulator described in the literature was Coley's Toxin, produced by Coley (1891). This was a mix of bacteria that typically resulted in fever and malaise after injection but oftentimes led to the reduction or elimination of the patients' tumors. Since then, research has uncovered mechanisms both by which host immune cells respond to such "toxins" and by which tumor cells act to suppress immune responses (Becker et al., 2013; Broz and Monack, 2013). A later bacteriallybased therapy was bacillus Calmette-Guerin (BCG), used as a tuberculosis vaccine and subsequently approved for treating bladder cancer (Vacchelli et al., 2013). Synthetic agents were also being developed such as imiquimod (Chen et al., 1988) and resiquimod (Tomai et al., 1995). Imiquimod (brand name Aldara) was approved in 1997 for the treatment of genital warts and certain skin cancers. Although such compounds are developed on an ongoing basis, the common theme is that as TLR agonists, they possess the ability to activate multiple immune-responserelated pathways simultaneously (Brown et al., 2011). This fuller spectrum of activation, in contrast to single-pathway treatment such as with Interferons, carries the potential to more effectively combat Francisella infection.

Monocytes express most TLR, although with low levels of TLR9 and virtually no TLR3 (Hornung et al., 2002), so it is likely that most immunomodulators will lead to their activation. Perhaps as importantly, activation of monocytes with these compounds can also indirectly elicit responses from neighboring cells. For example, the TLR7/8 agonist resiquimod promoted the production of IFN $\gamma$ from Natural Killer (NK) cells in vitro, but only through monocyte-derived IL-12 during co-culture (Hart et al., 2005). Direct or indirect effects on other cells have been well-documented as well. For example, resiquimod has been shown to promote dendritic cell maturation and antigen presentation (Ahonen et al., 1999), and treatment of PBMC with the TLR8-selective agonist VTX-2337 led to enhanced dendritic cell maturation as well as more effective priming of $\mathrm{CD}^{+} \mathrm{T}$ cells (Stephenson et al., 2013). Hence, although monocytes respond strongly to such agonists, functional responses in vivo and in humans will result from the culmination of direct and indirect responses among multiple cell types. Although immunomodulators continue to be developed, it may be beneficial to begin testing the efficacy of agents that are currently approved for other uses in humans. For example, BCG and even perhaps the topicallyapplied Imiquimod could be tested in mouse models. There are numerous mouse models of infection that can be utilized (Conlan et al., 2011), so a plethora of possibilities exists.

Other than the well-characterized side effects associated with the use of immunomodulators such as fever, nausea and malaise (Witt et al., 1993; Goldstein et al., 1998; Pockros et al., 2007; Weigel et al., 2012), there are additional considerations. For example, as demonstrated by Ireland et al. with macrophages (Ireland et al., 2010), the timing of immunomodulator administration may be a critical factor in the efficacy of treatment. With Francisella in particular, the more virulent F. tularensis Schu S4 has been shown to alter the expression and function of immune response factors. For example, most TLR (as well as the MyD88 adaptor protein) in monocytes are downregulated following infection with $F$. tularensis (Butchar et al., 2008). Similarly, it has been shown that $F$. tularensis can block NF- $\kappa \mathrm{B}$ activation, $\mathrm{PKB} /$ Akt phosphorylation and cytokine production in macrophages (Melillo et al., 2010). Hence, within the context of tularemia it would be hoped that enough monocytes/macrophages (and other cells) would come into contact with the agonist before encountering Francisella, such that a more effective immune response could be attained. Along with timing, it is important to consider that repeated dosages of immunomodulators may not be fully effective. Endotoxin tolerance following an initial stimulus can lead to hyporesponsiveness to subsequent stimuli (Greisman and Hornick, 1975; West and Heagy, 2002; Morris and Li, 2012). It has been shown in a mouse model of tumor immunotherapy that systemic administration of the TLR7/8 agonist resiquimod led to such hyporesponsiveness, which was overcome by altering the timing of repeated injections (Bourquin et al., 2011). Based on this, it seems probable that immunomodulators by themselves will not be fully effective against Francisella.

The use of therapeutic antibodies within the cancer field has been ongoing since 1997 with the advent of Rituximab, and several others are in use or testing for a variety of cancers. Much of their efficacy has been attributed to antibody-dependent cellular cytotoxicity (ADCC) (Sliwkowski et al., 1999; Clynes et al., 2000), which monocytes are capable of performing (Shaw et al., 1978). There have also been efforts to engineer these antibodies for better binding, and/or for drug delivery to target cells (Vincent and Zurini, 2012).

Antibodies within the context of Francisella have also been examined preclinically, with promising results. (Stenmark et al., 2003; Stenmark and Sjostedt, 2004). Of particular note, human serum from a person infected with $F$. tularensis holarctica was able to confer protection against $F$. tularensis holarctica in mice (Stenmark et al., 2003). Stenmark and Sjostedt went on to show that immune serum led to increases in both $\mathrm{TNF} \alpha$ and IL-12 (Stenmark and Sjostedt, 2004), which had been previously shown to be important within the context of Francisella infection (Stenmark et al., 1999). From a practical perspective, it may not be feasible to isolate anti-Francisella antibodies from people who survived infection and use them to treat currently-infected patients. In addition, there are currently few commercially-available antibodies against virulent $F$. tularensis. 
However, DNA-based technology has made the production of monoclonal antibodies far less cumbersome so it is not unreasonable to predict that a battery of humanized antibodies could be available in the future. Furthermore, as with several antitumor antibodies, such new anti-Francisella antibodies may be engineered to enhance binding and/or immunogenicity. Due to the immunosuppressive nature of $F$. tularensis, however, it is possible that anti-Francisella antibodies alone will not be fully effective for all patients.

Perhaps a combination of immunomodulators and antiFrancisella antibodies should be explored, as it has been shown that the two together can lead to superadditive immune responses. For example, we found that treatment of human monocytes with the TLR7/8 agonist resiquimod led to synergistic increases in IgG-mediated TNF $\alpha$ production. Resiquimod also enhanced monocyte-mediated ADCC against a tumor cell line and synergistically improved the efficacy of antitumor antibody therapy in vivo. Interestingly, resiquimod modulated not only the function but also the expression of monocyte Fc $\gamma$ receptors $(\mathrm{Fc} \gamma \mathrm{R})$, such that activating receptors were upregulated and the inhibitory FcyRIIb was downregulated (Butchar et al., 2010). Similarly, the TLR8-selective agonist VTX-2337 was shown to increase the effectiveness of NK cell-mediated ADCC ( $\mathrm{Lu}$ et al., 2012). Although not all TLR agonists may modulate monocyte $\mathrm{Fc} \gamma \mathrm{R}$ expression to equal extents, it is likely that at least one or more FDA-approved agents such as BCG could. Within the context of tularemia, this dual therapy might successfully combat the immunosuppressive effects of F. tularensis and direct the host immune cells specifically against this pathogen. It remains to be tested, however, whether such treatment can offset the Francisellamediated suppression seen upon contact and phagocytosis. Lastly, from a treatment point of view, the synergistic effects of dual treatment might permit the use of lower dosages and thereby minimize untoward effects.

\section{CONCLUSION}

Francisella has evolved methods to escape and suppress host cell immune responses. This might be counteracted via the use of immunomodulatory agents or antibodies, and the combination of both may lead to the best results. Further research may lead to the successful development and testing of such agents.

\section{ACKNOWLEDGMENTS}

This work was supported by the NIH/NIAID Regional Center of Excellence for Biodefense and Emerging Infectious Diseases Research (RCE) Program. The authors wish to acknowledge membership within and support from the Region V "Great Lakes" RCE (NIH award 1-U54-AI-057153).

\section{REFERENCES}

Ahonen, C. L., Gibson, S. J., Smith, R. M., Pederson, L. K., Lindh, J. M., Tomai, M. A., et al. (1999). Dendritic cell maturation and subsequent enhanced T-cell stimulation induced with the novel synthetic immune response modifier R-848. Cell Immunol. 197, 62-72. doi: 10.1006/cimm.1999.1555

Al Khodor, S., and Abu, K. Y. (2010). Triggering Ras signalling by intracellular Francisella tularensis through recruitment of PKCalpha and betaI to the SOS2/GrB2 complex is essential for bacterial proliferation in the cytosol. Cell Microbiol. 12, 1604-1621. doi: 10.1111/j.1462-5822.2010.01494.x
Allen, L. A., Beecher, B. R., Lynch, J. T., Rohner, O. V., and Wittine, L. M. (2005). Helicobacter pylori disrupts NADPH oxidase targeting in human neutrophils to induce extracellular superoxide release. J. Immunol. 174, 3658-3667.

Anthony, L. S., Ghadirian, E., Nestel, F. P., and Kongshavn, P. A. (1989). The requirement for gamma interferon in resistance of mice to experimental tularemia. Microb. Pathog. 7, 421-428. doi: 10.1016/0882-4010(89) 90022-3

Anthony, L. S., Morrissey, P. J., and Nano, F. E. (1992). Growth inhibition of Francisella tularensis live vaccine strain by IFN-gamma-activated macrophages is mediated by reactive nitrogen intermediates derived from L-arginine metabolism. J. Immunol. 148, 1829-1834.

Araki, N., Johnson, M. T., and Swanson, J. A. (1996). A role for phosphoinositide 3-kinase in the completion of macropinocytosis and phagocytosis by macrophages. J. Cell Biol. 135, 1249-1260. doi: 10.1083/jcb.135.5.1249

Asare, R., and Abu Kwaik, Y. (2010). Exploitation of host cell biology and evasion of immunity by francisella tularensis. Front. Microbiol. 1:145. doi: 10.3389/fmicb.2010.00145

Atianand, M. K., Duffy, E. B., Shah, A., Kar, S., Malik, M., and Harton, J. A. (2011). Francisella tularensis reveals a disparity between human and mouse NLRP3 inflammasome activation. J. Biol. Chem. 286, 39033-39042. doi: 10.1074/jbc.M111.244079

Becker, J. C., Andersen, M. H., Schrama, D., and Thor, S. P. (2013). Immunesuppressive properties of the tumor microenvironment. Cancer Immunol. Immunother. 62, 1137-1148. doi: 10.1007/s00262-013-1434-6

Bosio, C. M. (2011). The subversion of the immune system by francisella tularensis. Front. Microbiol. 2:9. doi: 10.3389/fmicb.2011.00009

Bosio, C. M., Bielefeldt-Ohmann, H., and Belisle, J. T. (2007). Active suppression of the pulmonary immune response by Francisella tularensis Schu4. J. Immunol. $178,4538-4547$.

Bourquin, C., Hotz, C., Noerenberg, D., Voelkl, A., Heidegger, S., Roetzer, L. C., et al. (2011). Systemic cancer therapy with a small molecule agonist of toll-like receptor 7 can be improved by circumventing TLR tolerance. Cancer Res. 71, 5123-5133. doi: 10.1158/0008-5472.CAN-10-3903

Brown, J., Wang, H., Hajishengallis, G. N., and Martin, M. (2011). TLR-signaling networks: an integration of adaptor molecules, kinases, and cross-talk. J. Dent. Res. 90, 417-427. doi: 10.1177/0022034510381264

Broz, P., and Monack, D. M. (2011). Molecular mechanisms of inflammasome activation during microbial infections. Immunol. Rev. 243, 174-190. doi: 10.1111/j.1600-065X.2011.01041.x

Broz, P., and Monack, D. M. (2013). Newly described pattern recognition receptors team up against intracellular pathogens. Nat. Rev. Immunol. 13, 551-565. doi: $10.1038 /$ nri3479

Butchar, J. P., Cremer, T. J., Clay, C. D., Gavrilin, M. A., Wewers, M. D., Marsh, C. B., et al. (2008). Microarray analysis of human monocytes infected with Francisella tularensis identifies new targets of host response subversion. PLOS ONE 3:e2924. doi: 10.1371/journal.pone.0002924

Butchar, J. P., Mehta, P., Justiniano, S. E., Guenterberg, K. D., Kondadasula, S. V., Mo, X., et al. (2010). Reciprocal regulation of activating and inhibitory Fc\{gamma\} receptors by TLR7/8 activation: implications for tumor immunotherapy. Clin. Cancer Res. 16, 2065-2075. doi: 10.1158/10780432.CCR-09-2591

Celli, J., and Zahrt, T. C. (2013). Mechanisms of Francisella tularensis intracellular pathogenesis. Cold Spring Harb. Perspect. Med. 3, a010314. doi: 10.1101/cshperspect.a010314

Chase, J. C., and Bosio, C. M. (2010). The presence of CD14 overcomes evasion of innate immune responses by virulent Francisella tularensis in human dendritic cells in vitro and pulmonary cells in vivo. Infect. Immun. 78, 154-167. doi: 10.1128/IAI.00750-09

Chase, J. C., Celli, J., and Bosio, C. M. (2009). Direct and indirect impairment of human dendritic cell function by virulent Francisella tularensis Schu S4. Infect. Immun. 77, 180-195. doi: 10.1128/IAI.00879-08

Chen, M., Griffith, B. P., Lucia, H. L., and Hsiung, G. D. (1988). Efficacy of S26308 against guinea pig cytomegalovirus infection. Antimicrob. Agents Chemother. 32, 678-683. doi: 10.1128/AAC.32.5.678

Chen, Q., Powell, D. W., Rane, M. J., Singh, S., Butt, W., Klein, J. B., et al. (2003). Akt phosphorylates p47phox and mediates respiratory burst activity in human neutrophils. J. Immunol. 170, 5302-5308.

Chiu, H. C., Yang, J., Soni, S., Kulp, S. K., Gunn, J. S., Schlesinger, L. S., et al. (2009). Pharmacological exploitation of an off-target antibacterial effect of the 
cyclooxygenase-2 inhibitor celecoxib against Francisella tularensis. Antimicrob. Agents Chemother. 53, 2998-3002. doi: 10.1128/AAC.00048-09

Chow, J. C., Young, D. W., Golenbock, D. T., Christ, W. J., and Gusovsky, F. (1999). Toll-like receptor-4 mediates lipopolysaccharide-induced signal transduction. J. Biol. Chem. 274, 10689-10692. doi: 10.1074/jbc.274.16.10689

Clemens, D. L., and Horwitz, M. A. (2007). Uptake and intracellular fate of Francisella tularensis in human macrophages. Ann. N.Y. Acad. Sci. 1105, 160-186. doi: 10.1196/annals.1409.001

Clynes, R. A., Towers, T. L., Presta, L. G., and Ravetch, J. V. (2000). Inhibitory Fc receptors modulate in vivo cytoxicity against tumor targets. Nat. Med. 6, 443-446. doi: 10.1038/74704

Coley, W. B. (1891). II. Contribution to the knowledge of sarcoma. Ann. Surg. 14, 199-220. doi: 10.1097/00000658-189112000-00015

Collazo, C. M., Sher, A., Meierovics, A. I., and Elkins, K. L. (2006). Myeloid differentiation factor-88 (MyD88) is essential for control of primary in vivo Francisella tularensis LVS infection, but not for control of intra-macrophage bacterial replication. Microbes Infect. 8, 779-790. doi: 10.1016/j.micinf.2005.09.014

Conlan, J. W., Chen, W., Bosio, C. M., Cowley, S. C., and Elkins, K. L. (2011). Infection of mice with Francisella as an immunological model. Curr. Protoc. Immunol. Chapter 19, Unit 19.14. doi: 10.1002/0471142735.im1914s93

Crane, D. D., Griffin, A. J., Wehrly, T. D., and Bosio, C. M. (2013). Bla cells enhance susceptibility to infection with virulent Francisella tularensis via modulation of NK/NKT cell responses. J. Immunol. 190, 2756-2766. doi: 10.4049/jimmunol.1202697

Cremer, T. J., Butchar, J. P., and Tridandapani, S. (2011). Francisella subverts innate immune signaling: focus on PI3K/Akt. Front. Microbiol. 5:13. doi: 10.3389/fmicb.2011.00013

Cremer, T. J., Ravneberg, D. H., Clay, C. D., Piper-Hunter, M. G., Marsh, C. B., Elton, T. S., et al. (2009). MiR-155 induction by F. novicida but not the virulent F. tularensis results in SHIP down-regulation and enhanced pro-inflammatory cytokine response. PLoS ONE 4:e8508. doi: 10.1371/journal.pone.0008508

Dai, S., Rajaram, M. V., Curry, H. M., Leander, R., and Schlesinger, L. S. (2013). Fine tuning inflammation at the front door: macrophage complement receptor 3mediates phagocytosis and immune suppression for Francisella tularensis. PLoS Pathog. 9:e1003114. doi: 10.1371/journal.ppat.1003114

Damen, J. E., Liu, L., Rosten, P., Humphries, R. K., Jefferson, A. B., Majerus, P. W., et al. (1996). The $145-\mathrm{kDa}$ protein induced to associate with Shc by multiple cytokines is an inositol tetraphosphate and phosphatidylinositol 3,4,5triphosphate 5-phosphatase. Proc. Natl. Acad. Sci. U.S.A. 93, 1689-1693. doi: 10.1073/pnas.93.4.1689

Dotson, R. J., Rabadi, S. M., Westcott, E. L., Bradley, S., Catlett, S. V., Banik, S., et al. (2013). Repression of inflammasome by francisella tularensis during early stages of infection. J. Biol. Chem. 288, 23844-23857. doi: 10.1074/jbc.M113.490086

Duenas, A. I., Aceves, M., Orduna, A., Diaz, R., Sanchez, C. M., and GarciaRodriguez, C. (2006). Francisella tularensis LPS induces the production of cytokines in human monocytes and signals via Toll-like receptor 4 with much lower potency than E. coli LPS. Int. Immunol. 18, 785-795. doi: 10.1093/intimm/dxl015

Elkins, K. L., Cowley, S. C., and Bosio, C. M. (2007). Innate and adaptive immunity to Francisella. Ann. N.Y. Acad. Sci. 1105, 284-324. doi: 10.1196/annals.1409.014

Eulalio, A., Schulte, L., and Vogel, J. (2012). The mammalian microRNA response to bacterial infections. RNA Biol. 9, 742-750. doi: 10.4161/rna.20018

Fernandes-Alnemri, T., Yu, J. W., Juliana, C., Solorzano, L., Kang, S., Wu, J., et al. (2010). The AIM2 inflammasome is critical for innate immunity to Francisella tularensis. Nat. Immunol. 11, 385-393. doi: 10.1038/ni.1859

Gallois, A., Klein, J. R., Allen, L. A., Jones, B. D., and Nauseef, W. M. (2001). Salmonella pathogenicity island 2-encoded type III secretion system mediates exclusion of NADPH oxidase assembly from the phagosomal membrane. J. Immunol. 166, 5741-5748.

Gavrilin, M. A., Bouakl, I. J., Knatz, N. L., Duncan, M. D., Hall, M. W., Gunn, J. S., et al. (2006). Internalization and phagosome escape required for Francisella to induce human monocyte IL-1beta processing and release. Proc. Natl. Acad. Sci. U.S A. 103, 141-146. doi: 10.1073/pnas.0504271103

Goldstein, D., Hertzog, P., Tomkinson, E., Couldwell, D., McCarville, S., Parrish, S., et al. (1998). Administration of imiquimod, an interferon inducer, in asymptomatic human immunodeficiency virus-infected persons to determine safety and biologic response modification. J. Infect. Dis. 178, 858-861. doi: $10.1086 / 515343$
Greisman, S. E., and Hornick, R. B. (1975). The nature of endotoxin tolerance. Trans. Am. Clin. Climatol. Assoc. 86, 43-50.

Greisman, S. E., Hornick, R. B., Carozza, F. A. Jr., and Woodward, T. E. (1963). The role of endotoxin during typhoid fever and tularemia in man. I. Acquisition of tolerance to endotoxin. J. Clin. Invest. 42, 1064-1075. doi: 10.1172/JCI104792

Hall, J. D., Woolard, M. D., Gunn, B. M., Craven, R. R., Taft-Benz, S., Frelinger, J. A., et al. (2008). Infected-host-cell repertoire and cellular response in the lung following inhalation of Francisella tularensis Schu S4, LVS, or U112. Infect. Immun. 76, 5843-5852. doi: 10.1128/IAI.01176-08

Hart, O. M., Athie-Morales, V., O'Connor, G. M., and Gardiner, C. M. (2005) TLR7/8-mediated activation of human NK cells results in accessory celldependent IFN-gamma production. J. Immunol. 175, 1636-1642.

Hemmings, B. A., and Restuccia, D. F. (2012). PI3K-PKB/Akt pathway. Cold Spring Harb. Perspect. Biol. 4, a011189. doi: 10.1101/cshperspect.a011189

Henry, T., Brotcke, A., Weiss, D. S., Thompson, L. J., and Monack, D. M. (2007). Type I interferon signaling is required for activation of the inflammasome during Francisella infection. J. Exp. Med. 204, 987-994. doi: 10.1084/jem.20062665

Hers, I., Vincent, E. E., and Tavare, J. M. (2011). Akt signalling in health and disease. Cell Signal. 23, 1515-1527. doi: 10.1016/j.cellsig.2011.05.004

Hornung, V., Rothenfusser, S., Britsch, S., Krug, A., Jahrsdorfer, B., Giese, T., et al. (2002). Quantitative expression of toll-like receptor 1-10 mRNA in cellular subsets of human peripheral blood mononuclear cells and sensitivity to CpG oligodeoxynucleotides. J. Immunol. 168, 4531-4537.

Hoyal, C. R., Gutierrez, A., Young, B. M., Catz, S. D., Lin, J. H., Tsichlis, P. N., et al. (2003). Modulation of p47PHOX activity by site-specific phosphorylation: Aktdependent activation of the NADPH oxidase. Proc. Natl. Acad. Sci. U.S.A. 100, 5130-5135. doi: 10.1073/pnas.1031526100

Hrstka, R., Stulik, J., and Vojtesek, B. (2005). The role of MAPK signal pathways during Francisella tularensis LVS infection-induced apoptosis in murine macrophages. Microbes Infect. 7, 619-625. doi: 10.1016/j.micinf.2004.12.020

Ireland, R., Olivares-Zavaleta, N., Warawa, J. M., Gherardini, F. C., Jarrett, C., Hinnebusch, B. J., et al. (2010). Effective, broad spectrum control of virulent bacterial infections using cationic DNA liposome complexes combined with bacterial antigens. PLoS Pathog. 6:e1000921. doi: 10.1371/journal.ppat. 1000921

Johansson, A., Celli, J., Conlan, W., Elkins, K. L., Forsman, M., Keim, P. S., et al. (2010). Objections to the transfer of Francisella novicida to the subspecies rank of Francisella tularensis. Int. J. Syst. Evol. Microbiol. 60(pt 8), 1717-1718. author reply: 1718-1720. doi: 10.1099/ijs.0.022830-0

Jones, C. L., Napier, B. A., Sampson, T. R., Llewellyn, A. C., Schroeder, M. R., and Weiss, D. S. (2012). Subversion of host recognition and defense systems by Francisella spp. Microbiol. Mol. Biol. Rev. 76, 383-404. doi: 10.1128/MMBR.05027-11

Jones, J. W., Kayagaki, N., Broz, P., Henry, T., Newton, K., O’Rourke, K., et al. (2010). Absent in melanoma 2 is required for innate immune recognition of Francisella tularensis. Proc. Natl. Acad. Sci. U.S A. 107, 9771-9776. doi: 10.1073/pnas. 1003738107

Katz, J., Zhang, P., Martin, M., Vogel, S. N., and Michalek, S. M. (2006). Toll-like receptor 2 is required for inflammatory responses to Francisella tularensis LVS. Infect. Immun. 74, 2809-2816. doi: 10.1128/IAI.74.5.2809-2816.2006

Keates, S., Sougioultzis, S., Keates, A. C., Zhao, D., Peek, R. M. Jr., Shaw, L. M., et al. (2001). cag+ Helicobacter pylori induce transactivation of the epidermal growth factor receptor in AGS gastric epithelial cells. J. Biol. Chem. 276, 48127-48134. doi: 10.1074/jbc.M107630200

Kushner, E. J., and Bautch, V. L. (2013). Building blood vessels in development and disease. Curr. Opin. Hematol. 20, 231-236. doi: 10.1097/MOH.0b013e328360614b

Leavy, O. (2012). Tumour immunology: a close-range dual hit for tumour immunity. Nat. Rev. Immunol. 12, 227. doi: 10.1038/nri3189

Lembo, A., Pelletier, M., Iyer, R., Timko, M., Dudda, J. C., West, T. E., et al. (2008). Administration of a synthetic TLR4 agonist protects mice from pneumonic tularemia. J. Immunol. 180, 7574-7581.

Lindgren, H., Stenman, L., Tarnvik, A., and Sjostedt, A. (2005). The contribution of reactive nitrogen and oxygen species to the killing of Francisella tularensis LVS by murine macrophages. Microbes Infect. 7, 467-475. doi: 10.1016/j.micinf.2004.11.020

Lu, H., Dietsch, G. N., Matthews, M. A., Yang, Y., Ghanekar, S., Inokuma, M., et al. (2012). VTX-2337 is a novel TLR8 agonist that activates NK cells and augments ADCC. Clin. Cancer Res. 18, 499-509. doi: 10.1158/1078-0432.CCR-11-1625 
Mailman, T. L., and Schmidt, M. H. (2005). Francisella philomiragia adenitis and pulmonary nodules in a child with chronic granulomatous disease. Can. J. Infect. Dis. Med. Microbiol. 16, 245-248.

Malik, M., Bakshi, C. S., Sahay, B., Shah, A., Lotz, S. A., and Sellati, T. J. (2006). Tolllike receptor 2 is required for control of pulmonary infection with Francisella tularensis. Infect. Immun. 74, 3657-3662. doi: 10.1128/IAI.02030-05

Mansell, A., Khelef, N., Cossart, P., and O’Neill, L. A. (2001). Internalin B activates nuclear factor-kappa B via Ras, phosphoinositide 3-kinase, and Akt. J. Biol. Chem. 276, 43597-43603. doi: 10.1074/jbc.M105202200

Mantia, L. L., Vacchi, L., Rovaris, M., Di Pietrantonj, C., Ebers, G., Fredrikson, S., et al. (2013). Interferon beta for secondary progressive multiple sclerosis: a systematic review. J. Neurol Neurosurg. Psychiatry 84, 420-426. doi: 10.1136/jnnp-2012-303291

Mariathasan, S., Weiss, D. S., Dixit, V. M., and Monack, D. M. (2005). Innate immunity against Francisella tularensis is dependent on the ASC/caspase-1 axis. J. Exp. Med. 202, 1043-1049. doi: 10.1084/jem.20050977

McCaffrey, R. L., and Allen, L. A. (2006). Francisella tularensis LVS evades killing by human neutrophils via inhibition of the respiratory burst and phagosome escape. J. Leukoc. Biol. 80, 1224-1230. doi: 10.1189/jlb.0406287

McCaffrey, R. L., Schwartz, J. T., Lindemann, S. R., Moreland, J. G., Buchan, B. W., Jones, B. D., et al. (2010). Multiple mechanisms of NADPH oxidase inhibition by type A and type B Francisella tularensis. J. Leukoc. Biol. 88, 791-805. doi: 10.1189/jlb.1209811

Medina, E. A., Morris, I. R., and Berton, M. T. (2010). Phosphatidylinositol 3kinase activation attenuates the TLR2-mediated macrophage proinflammatory cytokine response to Francisella tularensis live vaccine strain. J. Immunol. 185, 7562-7572. doi: 10.4049/jimmunol.0903790

Melillo, A. A., Bakshi, C. S., and Melendez, J. A. (2010). Francisella tularensis antioxidants harness reactive oxygen species to restrict macrophage signaling and cytokine production. J. Biol. Chem. 285, 27553-27560. doi: 10.1074/jbc.M110.144394

Melillo, A. A., Mahawar, M., Sellati, T. J., Malik, M., Metzger, D. W., Melendez, J. A., et al. (2009). Identification of Francisella tularensis live vaccine strain $\mathrm{CuZn}$ superoxide dismutase as critical for resistance to extracellularly generated reactive oxygen species. J. Bacteriol. 191, 6447-6456. doi: 10.1128/JB.00534-09

Mohapatra, N. P., Soni, S., Rajaram, M. V., Dang, P. M., Reilly, T. J., El Benna, J., et al. (2010). Francisella acid phosphatases inactivate the NADPH oxidase in human phagocytes. J. Immunol. 184, 5141-5150. doi: 10.4049/jimmunol.0903413

Mohapatra, N. P., Soni, S., Rajaram, M. V., Strandberg, K. L., and Gunn, J. S. (2013). Type A Francisella tularensis acid phosphatases contribute to pathogenesis. PLoS ONE 8:e56834. doi: 10.1371/journal.pone.0056834

Morris, M., and Li, L. (2012). Molecular mechanisms and pathological consequences of endotoxin tolerance and priming. Arch. Immunol. Ther. Exp. (Warsz) 60, 13-18. doi: 10.1007/s00005-011-0155-9

Moser, B., and Loetscher, P. (2001). Lymphocyte traffic control by chemokines. Nat. Immunol. 2, 123-128. doi: 10.1038/84219

Nylund, A., Ottem, K. F., Watanabe, K., Karlsbakk, E., and Krossoy, B. (2006). Francisella sp. (Family Francisellaceae) causing mortality in Norwegian cod (Gadus morhua) farming. Arch. Microbiol. 185, 383-392. doi: 10.1007/s00203006-0109-5

Park, S. W., Kim, H. S., Hah, J. W., Jeong, W. J., Kim, K. H., and Sung, M. W. (2010). Celecoxib inhibits cell proliferation through the activation of ERK and p38 MAPK in head and neck squamous cell carcinoma cell lines. Anticancer Drugs 21, 823-830. doi: 10.1097/CAD.0b013e32833dada8

Parsa, K. V., Butchar, J. P., Rajaram, M. V., Cremer, T. J., Gunn, J. S., Schlesinger, L. S., et al. (2008a). Francisella gains a survival advantage within mononuclear phagocytes by suppressing the host IFNgamma response. Mol. Immunol. 45, 3428-3437. doi: 10.1016/j.molimm.2008.04.006

Parsa, K. V., Butchar, J. P., Rajaram, M. V., Cremer, T. J., and Tridandapani, S. (2008b). The tyrosine kinase Syk promotes phagocytosis of Francisella through the activation of Erk. Mol. Immunol. 45, 3012-3021. doi: 10.1016/j.molimm.2008.01.011

Parsa, K. V., Ganesan, L. P., Rajaram, M. V., Gavrilin, M. A., Balagopal, A., Mohapatra, N. P., et al. (2006). Macrophage pro-inflammatory response to Francisella novicida infection is regulated by SHIP. PLoS Pathog. 2:e71. doi: 10.1371/journal.ppat.0020071

Petiot, A., Ogier-Denis, E., Blommaart, E. F., Meijer, A. J., and Codogno, P. (2000). Distinct classes of phosphatidylinositol $3^{\prime}$-kinases are involved in signaling pathways that control macroautophagy in HT-29 cells. J. Biol. Chem. 275, 992-998. doi: 10.1074/jbc.275.2.992

Phillips, N. J., Schilling, B., McLendon, M. K., Apicella, M. A., and Gibson, B. W. (2004). Novel modification of lipid A of Francisella tularensis. Infect. Immun. 72, 5340-5348. doi: 10.1128/IAI.72.9.5340-5348.2004

Pockros, P. J., Guyader, D., Patton, H., Tong, M. J., Wright, T., Mchutchison, J. G., et al. (2007). Oral resiquimod in chronic HCV infection: safety and efficacy in 2 placebo-controlled, double-blind phase IIa studies. J. Hepatol. 47, 174-182. doi: 10.1016/j.jhep.2007.02.025

Polsinelli, T., Meltzer, M. S., and Fortier, A. H. (1994). Nitric oxide-independent killing of Francisella tularensis by IFN-gamma-stimulated murine alveolar macrophages. J. Immunol. 153, 1238-1245.

Qin, A., and Mann, B. J. (2006). Identification of transposon insertion mutants of Francisella tularensis tularensis strain Schu S4 deficient in intracellular replication in the hepatic cell line HepG2. BMC Microbiol. 6:69. doi: 10.1186/14712180-6-69

Qin, A., Scott, D. W., Rabideau, M. M., Moore, E. A., and Mann, B. J. (2011). Requirement of the CXXC motif of novel Francisella infectivity potentiator protein B FipB, and FipA in virulence of F. tularensis subsp. tularensis. PLoS ONE 6:e24611. doi: 10.1371/journal.pone.0024611

Qureshi, S. T., Lariviere, L., Leveque, G., Clermont, S., Moore, K. J., Gros, P., et al. (1999). Endotoxin-tolerant mice have mutations in Toll-like receptor 4 (Tlr4). J. Exp. Med. 189, 615-625. doi: 10.1084/jem.189.4.615

Rajaram, M. V., Ganesan, L. P., Parsa, K. V., Butchar, J. P., Gunn, J. S., and Tridandapani, S. (2006). Akt/Protein kinase B modulates macrophage inflammatory response to Francisella infection and confers a survival advantage in mice. J. Immunol. 177, 6317-6324.

Rathinam, V. A., Jiang, Z., Waggoner, S. N., Sharma, S., Cole, L. E., Waggoner, L., et al. (2010). The AIM2 inflammasome is essential for host defense against cytosolic bacteria and DNA viruses. Nat. Immunol. 11, 395-402. doi: 10.1038/ni.1864

Rick, L. C., and Wu, T. H. (2007). Animal models of Francisella tularensis infection. Ann. N.Y. Acad. Sci. 1105, 238-265. doi: 10.1196/annals.1409.003

Sakai, K., Suzuki, H., Oda, H., Akaike, T., Azuma, Y., Murakami, T., et al. (2006). Phosphoinositide 3-kinase in nitric oxide synthesis in macrophage: critical dimerization of inducible nitric-oxide synthase. J. Biol. Chem. 281, 17736-17742. doi: 10.1074/jbc.M601896200

Sandstrom, G., Tarnvik, A., and Wolf-Watz, H. (1987). Immunospecific Tlymphocyte stimulation by membrane proteins from Francisella tularensis. J. Clin. Microbiol. 25, 641-644.

Santic, M., Molmeret, M., and Abu, K. Y. (2005). Modulation of biogenesis of the Francisella tularensis subsp. novicida-containing phagosome in quiescent human macrophages and its maturation into a phagolysosome upon activation by IFN-gamma. Cell Microbiol. 7, 957-967. doi: 10.1111/j.14625822.2005.00529.x

Savva, A., and Roger, T. (2013). Targeting toll-like receptors: promising therapeutic strategies for the management of sepsis-associated pathology and infectious diseases. Front. Immunol. 4:387. doi: 10.3389/fimmu.2013.00387

Schmid, G. P., Catino, D., Suffin, S. C., Martone, W. J., and Kaufmann, A. F. (1983). Granulomatous pleuritis caused by Francisella tularensis: possible confusion with tuberculous pleuritis. Am. Rev. Respir. Dis. 128, 314-316.

Seger, R. A., Hollis, D. G., Weaver, R. E., and Hitzig, W. H. (1982). Chronic granulomatous disease: fatal septicemia caused by an unnamed gram-negative bacterium. J. Clin. Microbiol. 16, 821-825.

Shaw, G. M., Levy, P. C., and Lobuglio, A. F. (1978). Human monocyte cytotoxicity to tumor cells. I. Antibody-dependent cytotoxicity. J. Immunol. 121, 573-578.

Sjostedt, A. (2003). Virulence determinants and protective antigens of Francisella tularensis. Curr. Opin. Microbiol. 6, 66-71. doi: 10.1016/S1369-5274(03) 00002-X

Sjostedt, A. (2007). Tularemia: history, epidemiology, pathogen physiology, and clinical manifestations. Ann. N.Y. Acad. Sci. 1105, 1-29. doi: 10.1196/annals.1409.009

Sjostedt, A., Sandstrom, G., Tarnvik, A., and Jaurin, B. (1989). Molecular cloning and expression of a T-cell stimulating membrane protein of Francisella tularensis. Microb. Pathog. 6, 403-414. doi: 10.1016/0882-4010(89)90082-X

Sjostedt, A., Tarnvik, A., and Sandstrom, G. (1991). The T-cell-stimulating 17-kilodalton protein of Francisella tularensis LVS is a lipoprotein. Infect. Immun. 59, 3163-3168. 
Sliwkowski, M. X., Lofgren, J. A., Lewis, G. D., Hotaling, T. E., Fendly, B. M., and Fox, J. A. (1999). Nonclinical studies addressing the mechanism of action of trastuzumab (Herceptin). Semin. Oncol. 26, 60-70.

Spiegel, R. J. (1985). INTRON A (interferon alfa-2b): clinical overview. Cancer Treat. Rev. 12 (Suppl. B), 5-16.

Stenmark, S., Lindgren, H., Tarnvik, A., and Sjostedt, A. (2003). Specific antibodies contribute to the host protection against strains of Francisella tularensis subspecies holarctica. Microb. Pathog. 35, 73-80. doi: 10.1016/S08824010(03)00095-0

Stenmark, S., and Sjostedt, A. (2004). Transfer of specific antibodies results in increased expression of TNF-alpha and IL12 and recruitment of neutrophils to the site of a cutaneous Francisella tularensis infection. J. Med. Microbiol. 53, 501-504. doi: 10.1099/jmm.0.05352-0

Stenmark, S., Sunnemark, D., Bucht, A., and Sjostedt, A. (1999). Rapid local expression of interleukin-12, tumor necrosis factor alpha, and gamma interferon after cutaneous Francisella tularensis infection in tularemia-immune mice. Infect. Immun. 67, 1789-1797.

Stephenson, R. M., Lim, C. M., Matthews, M., Dietsch, G., Hershberg, R., and Ferris, R. L. (2013). TLR8 stimulation enhances cetuximab-mediated natural killer cell lysis of head and neck cancer cells and dendritic cell cross-priming of EGFR-specific CD8(+) T cells. Cancer Immunol. Immunother. 62, 1347-1357. doi: 10.1007/s00262-013-1437-3

Telepnev, M., Golovliov, I., Grundstrom, T., Tarnvik, A., and Sjostedt, A. (2003). Francisella tularensis inhibits Toll-like receptor-mediated activation of intracellular signalling and secretion of TNF-alpha and IL-1 from murine macrophages. Cell Microbiol. 5, 41-51. doi: 10.1046/j.1462-5822.2003.00251.x

Telepnev, M., Golovliov, I., and Sjostedt, A. (2005). Francisella tularensis LVS initially activates but subsequently down-regulates intracellular signaling and cytokine secretion in mouse monocytic and human peripheral blood mononuclear cells. Microb. Pathog. 38, 239-247. doi: 10.1016/j.micpath.2005.02.003

Thakran, S., Li, H., Lavine, C. L., Miller, M. A., Bina, J. E., Bina, X. R., et al. (2008). Identification of Francisella tularensis lipoproteins that stimulate the toll-like receptor (TLR) 2/TLR1 heterodimer. J. Biol. Chem. 283, 3751-3760. doi: 10.1074/jbc.M706854200

Todd, P. A., and Goa, K. L. (1992). Interferon gamma-1b. A review of its pharmacology and therapeutic potential in chronic granulomatous disease. Drugs 43, 111-122. doi: 10.2165/00003495-199243010-00008

Tomai, M. A., Gibson, S. J., Imbertson, L. M., Miller, R. L., Myhre, P. E., Reiter, M. J., et al. (1995). Immunomodulating and antiviral activities of the imidazoquinoline S-28463. Antiviral Res. 28, 253-264. doi: 10.1016/0166-3542(95)00054-P

Vacchelli, E., Eggermont, A., Sautes-Fridman, C., Galon, J., Zitvogel, L., Kroemer, G., et al. (2013). Trial Watch: toll-like receptor agonists for cancer therapy. Oncoimmunology 2, e25238. doi: 10.4161/onci.25238

Vincent, K. J., and Zurini, M. (2012). Current strategies in antibody engineering: Fc engineering and $\mathrm{pH}$-dependent antigen binding, bispecific antibodies and antibody drug conjugates. Biotechnol. J. 7, 1444-1450. doi: 10.1002/biot.201200250
Waller, E. K. (2007). The role of sargramostim (rhGM-CSF) as immunotherapy. Oncologist 12(Suppl. 2), 22-26. doi: 10.1634/theoncologist. 12-S2-22

Weigel, B. J., Cooley, S., Defor, T., Weisdorf, D. J., Panoskaltsis-Mortari, A., Chen, W., et al. (2012). Prolonged subcutaneous administration of $852 \mathrm{~A}$, a novel systemic toll-like receptor 7 agonist, to activate innate immune responses in patients with advanced hematologic malignancies. Am. J. Hematol. 87, 953-956. doi: 10.1002/ajh.23280

Welsh, R. M., Bahl, K., Marshall, H. D., and Urban, S. L. (2012). Type 1 interferons and antiviral CD8 T-cell responses. PLoS Pathog. 8:e1002352. doi: 10.1371/journal.ppat.1002352

West, M. A., and Heagy, W. (2002). Endotoxin tolerance: a review. Crit. Care Med. 30, S64-S73. doi: 10.1097/00003246-200201001-00009

Whipp, M. J., Davis, J. M., Lum, G., De Boer, J., Zhou, Y., Bearden, S. W., et al. (2003). Characterization of a novicida-like subspecies of Francisella tularensis isolated in Australia. J. Med. Microbiol. 52, 839-842. doi: 10.1099/jmm.0. 05245-0

Wickstrum, J. R., Bokhari, S. M., Fischer, J. L., Pinson, D. M., Yeh, H. W., Horvat, R. T., et al. (2009). Francisella tularensis induces extensive caspase-3 activation and apoptotic cell death in the tissues of infected mice. Infect. Immun. 77, 4827-4836. doi: 10.1128/IAI.00246-09

Williams, M. A., White, S. A., Miller, J. J., Toner, C., Withington, S., Newland, A. C., et al. (1998). Granulocyte-macrophage colony-stimulating factor induces activation and restores respiratory burst activity in monocytes from septic patients. J. Infect. Dis. 177, 107-115. doi: 10.1086/513802

Witt, P. L., Ritch, P. S., Reding, D., McAuliffe, T. L., Westrick, L., Grossberg, S. E., et al. (1993). Phase I trial of an oral immunomodulator and interferon inducer in cancer patients. Cancer Res. 53, 5176-5180.

Conflict of Interest Statement: The authors declare that the research was conducted in the absence of any commercial or financial relationships that could be construed as a potential conflict of interest.

Received: 15 December 2013; paper pending published: 16 January 2014; accepted: 02 February 2014; published online: 21 February 2014.

Citation: Gillette DD, Tridandapani S and Butchar JP (2014) Monocyte/macrophage inflammatory response pathways to combat Francisella infection: possible therapeutic targets? Front. Cell. Infect. Microbiol. 4:18. doi: 10.3389/fcimb.2014.00018

This article was submitted to the journal Frontiers in Cellular and Infection Microbiology.

Copyright (c) 2014 Gillette, Tridandapani and Butchar. This is an open-access article distributed under the terms of the Creative Commons Attribution License (CC BY). The use, distribution or reproduction in other forums is permitted, provided the original author(s) or licensor are credited and that the original publication in this journal is cited, in accordance with accepted academic practice. No use, distribution or reproduction is permitted which does not comply with these terms. 